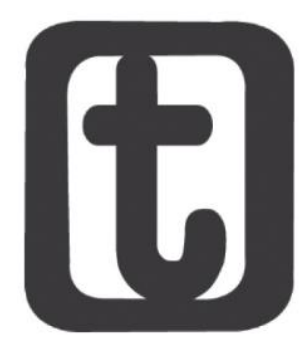

\title{
NA FRONTEIRA ENTRE O PÚBLICO E O PRIVADO: A PROTEÇÃO SOCIAL PARA PESSOAS COM DEFICIÊNCIA NO DISTRITO FEDERAL
}

On the frontier between the public and the private: social protection in the Federal District for people with disabilities

\author{
Thaís Kristosch Imperatori* \\ https://orcid.org/0000-0003-4536-5698 \\ Angela Vieira Neves** \\ https://orcid.org/0000-0002-3533-4794
}

\begin{abstract}
RESUMO
O presente artigo analisa as relações entre Estado e sociedade civil na proteção social para pessoas com deficiência no Distrito Federal (DF). A pesquisa possui caráter qualitativo e utiliza dados obtidos por meio de pesquisa documental em leis, decretos e demais atos normativos e de entrevistas a gestores públicos e de entidades da sociedade civil. Os dados mostram a existência de amplo marco legal que legitima a atuação de entidades da sociedade civil na oferta de serviços no campo da proteção social para pessoas com deficiência desde os anos 1980 e que tem se aprofundado nos anos mais recentes a partir de parcerias e convênios. A análise dos dados compreende os significados da relação entre Estado e sociedade civil, o repasse de recursos públicos a entidades privadas e a atuação do voluntariado nessas organizações. Como conclusões destaca-se a histórica desresponsabilização do Estado na proteção social para as pessoas com deficiência diante da atuação de entidades da sociedade civil. Também são analisados os limites dessa estrutura de atendimento na garantia de direitos a este público.
\end{abstract}

\section{PALAVRAS CHAVE}

Pessoas com deficiência, Deficiência, Proteção social, Sociedade civil, Estado

\begin{abstract}
* Assistente Social. Doutora em Política Social. Professora do Departamento de Serviço Social da Universidade de Brasília (UnB, Brasília (DF), Brasil). Campus Universitário Darcy Ribeiro, Instituto Central de Ciências Sala B1 606, Brasília-DF, CEP 70.910-900. E-mail: thaisimperatori@unb.com.br.

${ }^{* *}$ Assistente Social. Doutora em Ciências Sociais. Professora aposentada do Departamento de Serviço Social da Universidade de Brasília, Professora colaboradora do Programa de Pós-Graduação em Política Social da UnB. (PPGPS/SER/UnB, Brasília (DF), Brasil). Campus Universitário Darcy Ribeiro, Instituto Central de Ciências Sala B1 606, Brasília-DF, CEP 70.910-900. E-mail: angelaneves@unb.br.
\end{abstract}

DOI 10.22422/temporalis.2021v21n41p286-302 Creative Commons Atribuição 4.0 Internacional (https://creativecommons.org/licenses/by/4.0/deed.pt BR), que permite copiar e redistribuir o material em qualquer suporte ou formato, bem como adaptar, transformar e criar a partir deste material para qualquer fim, mesmo que comercial. O licenciante não pode revogar estes direitos desde que você respeite os termos da licença.

Temporalis, Brasília (DF), ano 21, n. 41, p. 286-302, jan./jun. 2021. | ISSN 2238-1856 
NA FRONTEIRA ENTRE O PÚBLICO E O PRIVAdo teMPOP Olif

\begin{abstract}
The current article analyzes the relationships between the State and the civil society in relation to the social protection of people with disabilities on the Federal District (FD). This research is qualitative and uses data obtained through documental search of laws, decrees and other normative acts, and interviews with public managers and civil society entities. The data shows the existence of a broad legal mark that legitimates the acting of the civil society on the service offers on the field of social protection for people with disabilities since the 1980 's, which has been intensified in more recent years with the establishment of partnerships and covenants. Data analysis comprehend the meaning of the relationship between the State and the civil society, transfer of public funds to private entities and the role of volunteering on these organizations. We concluded that there was a marked historical deresponsibilization of the State on the social protection of disabled people in the face social civil entities acting. In addition, we have also analyzed the limits of this attendance structure in guaranteeing public rights for disabled people.
\end{abstract}

\title{
KEYWORDS
}

People with disability, Disability, Social protection, Social society, State

\section{INTRODUÇÃO}

$\mathrm{O}$ s debates sobre a relação entre Estado e sociedade civil na proteção social são amplos. Isso porque não há um modelo único, mas várias formas de proteção social que se apresentam na trajetória histórica, ora com inspiração piedosa, como a caridade enquanto virtude cristã, ora como virtude altruística ou de deveres morais no campo da beneficência, da filantropia e da assistência privada. A ação do Estado na proteção social tem se consolidado no pós-segunda Guerra Mundial em alguns países da Europa (PEREIRA, 2016).

O presente artigo tem o objetivo de analisar as relações construídas entre Estado e sociedade civil na prestação de serviços de proteção social para pessoas com deficiência no Distrito Federal (DF). Para tanto, é importante reconhecer que no contexto brasileiro, até os anos 1980, as pessoas com deficiência eram atendidas majoritariamente por instituições filantrópicas e religiosas. As ações de proteção e cuidado situavam-se na esfera do assistencialismo, de práticas caritativas e cuidados familiares, com uma ausência de ações diretas do Estado para atendimento a este público (CABRAL FILHO; FERREIRA, 2013; FIGUEIRA, 2008; MAIOR, 1997).

Essa realidade começa a mudar com a mobilização das pessoas com deficiência enquanto um movimento político com luta reivindicatória por direitos e cidadania, possibilitando uma ruptura com o histórico de invisibilidade e segregação social (CABRAL FILHO; FERREIRA, 2013; DINIZ, SANTOS, 2010; LANNA JÚNIOR, 2010). Ocorre aí um processo de "cidadanização" das pessoas com deficiência, nos termos de Gadelha, Crespo e Ribeiro (2011, p. 26), quando elas passam a falar por si mesmas e se fazem ouvir.

Os resultados dessa articulação se materializaram na Constituição Federal de 1988, quando a deficiência tornou-se uma questão incorporada à proteção social pública, sendo reconhecida como responsabilidade do Estado. Isso significa a possibilidade de construção de políticas sociais com a garantia de direitos. Não ocorre, porém, uma suspensão total do modelo anterior de atendimento, que assume novas facetas. 
Na década de 1990, com o advento do projeto neoliberal no cenário brasileiro, a participação da sociedade civil passa a ocupar maior espaço na oferta de serviços públicos por meio da refilantropização do trato com a questão social (MONTAÑO, 1999; YASBEK, 1995). Vivencia-se um período de expansão de Organizações NãoGovernamentais e associações voluntárias, com o apelo à filantropia e à solidariedade social. Sociedade civil torna-se sinônimo de terceiro setor e vai se consolidando enquanto ator fundamental nas políticas sociais brasileiras.

A sociedade civil assume diferentes expressões e estabelece relações com o Estado que oscilam entre a parceria, inclusive por meio de transferência de recursos público para prestação de serviços; e uma ação reivindicatória e de controle democrático na luta pela ampliação de direitos e serviços públicos. Tem-se aí distintas formas de participação (NOGUEIRA, 2011).

No DF, esse processo de ampla participação de entidades da sociedade civil no campo da proteção social é verificado em diversas áreas, com destaque para a infância e adolescência (COELHO et al., 2001), a prestação de serviço na modalidade de abrigo (SOUZA, 2001) e na política de assistência social (FERREIRA, 2012; DUARTE, 2013). No presente artigo problematizam-se as relações entre público e privado no campo da proteção social para as pessoas com deficiência a partir do marco legal vigente e dos discursos de gestores públicos e de entidades da sociedade civil.

\section{METODOLOGIA}

Os dados analisados neste artigo se referem a um recorte da pesquisa qualitativa intitulada Entre o direito e a filantropia: a proteção social para pessoas com deficiência no Distrito Federal, na qual foram realizadas entrevistas com 38 gestores públicos e de entidades da sociedade civil que atuam na área de defesa e proteção das pessoas com deficiência no DF no período entre novembro de 2016 e agosto de 2017. Também utilizou-se a técnica da pesquisa documental em leis, decretos e demais atos normativos identificados por meio do Sistema Integrado de Normas Jurídicas do Distrito Federal.

Os critérios de escolha das entidades participantes da pesquisa foram qualitativos, destacando-se serem gerenciadas pela sociedade civil em suas diversas expressões, a partir da dupla negação de não ser governamental e não ser lucrativa (LANDIM, 2003; MESTRINER, 2001), bem como ter "[...] caráter eminentemente social" (BLANCO, 2002, p. 16). Ademais, considerou-se como critérios: o tempo de existência; o histórico de participação em espaços participativos como conselhos, conferências e demais fóruns; e a prestação de serviços ou realização de projetos específicos que atendam o público das pessoas com deficiência.

Destaca-se que neste artigo optou-se por utilizar a terminologia pessoas com deficiência, em consonância com a Convenção Internacional dos Direitos das Pessoas com Deficiência. Entretanto, ocasionalmente poderão ser mantidos os termos pessoas portadoras de deficiência e pessoas com necessidades especiais, tal qual presentes em leis e documentos oficiais.

Temporalis, Brasília (DF), ano 21, n. 41, p. 286-302, jan./jun. 2021. | ISSN 2238-1856 


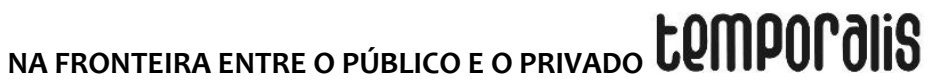

\section{O MARCO LEGAL}

Ainda nas primeiras regulamentações sobre a proteção social para pessoas com deficiência no DF vemos a previsão de atuação conjunta de órgãos e entidades da administração púbica com a iniciativa privada, a exemplo do Decreto $n^{\circ} 11.107 / 1988$ (DISTRITO FEDERAL, 1988), que dispõe sobre as ações da Administração do DF relativas às pessoas portadoras de deficiência e dá outras providências. Em um cenário de inexistência de ações públicas, tem-se o apoio governamental a entidades particulares que desenvolvem atividades voltadas à integração desse público:

\begin{abstract}
Art. $5^{\circ} \mathrm{Na}$ articulação, acompanhamento, controle e avaliação da elaboração e execução dos planos e programas relativos ao deficiente, a cargo de órgãos ou entidades da Administração do Distrito Federal ou da iniciativa privada, com a interveniência do Governo, a CORDE/DF deverá: I - contar com a efetiva participação das pessoas e entidades interessadas;

II - considerar a necessidade de prestar efetivo apoio às entidades particulares que desenvolvem atividades voltadas à integração social das pessoas portadoras de deficiência (DISTRITO FEDERAL, 1988, não paginado, grifos nossos).
\end{abstract}

A Lei Orgânica do DF (LODF), publicada em 1993, reitera essa compreensão ao afirmar a possibilidade do poder público de estabelecer convênios, contratos e outras formas de cooperação com entidades beneficentes ou privadas sem fins lucrativos para a execução de serviços, dentre outras áreas, para as pessoas com deficiência. Tais formas de atuação conjunta destinam-se inclusive para apoio técnico e financeiro a serviços que seriam executados no campo da política de assistência social descentralizada, principalmente aqueles destinados à população de baixa renda.

Art. 218. Compete ao Poder Público, na forma da lei e por intermédio da Secretaria competente, coordenar, elaborar e executar política de assistência social descentralizada e articulada com órgãos públicos e entidades sociais sem fins lucrativos, com vistas a assegurar especialmente:

I - apoio técnico e financeiro para programas de caráter sócio-educativos desenvolvidos por entidades beneficentes e de iniciativa de organizações comunitárias;

II - serviços assistenciais de proteção e defesa aos segmentos da população de baixa renda como:

a) alojamento e apoio técnico e social para mendigos, gestantes, egressos de prisões ou de manicômios, portadores de deficiência, migrantes e pessoas vítimas de violência doméstica e prostituídas;

b) gratuidade de sepultamento e dos meios e procedimentos a ele necessários;

c) apoio a entidades representativas da comunidade na criação de creches e pré-escolas comunitárias, conforme o disposto no art. 221;

d) atendimento a criança e adolescente;

e) atendimento a idoso e à pessoa portadora de deficiência, na comunidade (DISTRITO FEDERAL, 1993, não paginado, grifos nossos).

A publicação do Estatuto do Portador de Necessidades Especiais do DF, Lei $\mathrm{n}^{\circ}$ 3.939/2007, torna ainda mais explícita a relação entre governo e entidades da 
sociedade civil por meio de convênios, que materializam mecanismos de apoio e repasses de recursos, ao dispor que: "Art. 50 A execução das políticas públicas voltadas para a pessoa portadora de necessidades especiais no âmbito do Distrito Federal, com o apoio de organizações não-governamentais, deverá dar-se de forma articulada, por meio de convênio, destinada a evitar sobreposição de ações" (DISTRITO FEDERAL, 2007, não paginado, grifos nossos).

É importante situar que no cenário nacional, em 2004, foi instituído o Sistema Único de Assistência Social (SUAS), por meio da Política Nacional de Assistência Social (BRASIL, 2009). Tendo como referência a Constituição Federal e a Lei Orgânica da Assistência Social (Lei 8.742/1993) assim como diretrizes aprovadas na IV Conferência Nacional de Assistência Social ocorrida em 2003, buscou-se consolidá-la como política pública e direito social. Nesse sentido, colocam-se como diretrizes: a descentralização político-administrativa; a participação da população, por meio de entidades representativas, na formulação das políticas e controle das ações em todos os níveis; a primazia da responsabilidade do Estado na condução da Política de Assistência Social em cada esfera de governo e; a centralização da família para concepção e implementação dos benefícios, serviços, programas e projetos.

Ocorre que a previsão de primazia da responsabilidade do Estado se refere à condução da política e não necessariamente à execução de serviços e programas, tendo a previsão de complementariedade entre ações governamentais e nãogovernamentais na rede socioassistencial. Tem-se aí uma nova perspectiva de relação entre Estado e sociedade civil:

\footnotetext{
A gravidade dos problemas sociais brasileiros exige que o Estado assuma a primazia da responsabilidade em cada esfera de governo na condução da política. Por outro lado, a sociedade civil participa como parceira, de forma complementar na oferta de serviços, programas, projetos e benefícios de Assistência Social. Possui, ainda, o papel de exercer o controle social sobre a mesma (BRASIL, 2009, p. 47),
}

Em 2008, foi instituída a Política de Assistência Social do DF, conforme a Lei $\mathrm{n}^{\circ}$ 4.176/2008. Nela, a deficiência é apresentada como um elemento de vulnerabilidade, tornando as pessoas com deficiência como um dos públicos-alvo dos serviços. Essa ideia de vulnerabilidade é permeada por controversas. Mello (2016, p. 3274) chama atenção que "[...] as pessoas com deficiência são intrínseca e socialmente vulneráveis". Isso porque a vulnerabilidade está associada tanto ao contexto socioeconômico quanto a características específicas dos indivíduos ou populações. Nesse sentido, é um indicador de desigualdade social, que se expressa em processos de exclusão de grupos sociais que têm sua capacidade de ação e reação reduzida em virtude de discriminações e opressões, e não como sinônimo de incapacidade.

Esta Política deixa também clara a relação entre poder público e as entidades da sociedade civil na prestação de serviços ao definir a rede socioassistencial do SUAS:

Art. 33. Entende-se por rede socioassistencial do SUAS no Distrito Federal o conjunto integrado e articulado de ações de iniciativa pública e da 
sociedade, sob a coordenação do poder público, que ofertam e operam serviços, programas, projetos e benefícios socioassistenciais hierarquizados por proteção social e por níveis de complexidade.

Art. 34. O disposto nesta Lei aplica-se também às entidades e organizações de assistência social da rede socioassistencial do Distrito Federal, para a oferta complementar de serviços, programas, projetos e benefícios socioassistenciais no âmbito do Distrito Federal, que deverão adotar as medidas necessárias para adequação de seu funcionamento aos princípios e diretrizes do SUAS e suas regulações (DISTRITO FEDERAL, 2008, não paginado, grifos nossos).

Ainda é importante mencionar a Política Distrital para Integração da Pessoa com Deficiência, instituída pela Lei $n^{\circ}$ 4.317/2009 (DISTRITO FEDERAL, 2009), que também apresenta como um dos fundamentos da política de atendimento a este público a adoção de mecanismos de articulação entre órgãos públicos e entidades privadas para a implantação de parcerias.

Tem-se, portanto, um projeto político segundo o qual a proteção social para pessoas com deficiência é construída a partir de uma relação de parceria e de complementariedade entre Estado e sociedade civil. Tal projeto está em consonância com a realidade brasileira, que tem apontado para a ampliação da atuação das entidades da sociedade civil e do chamado terceiro setor (MONTAÑO, 2010; LAURELL, 1995; NEVES, 2007; YASBEK, 1995; TEIXEIRA, 2002).

Segundo o Plano Distrital de Políticas Públicas para Pessoas com Deficiência - Viver sem Limites DF (DISTRITO FEDERAL, 2013), as ações de habilitação e reabilitação e o acolhimento institucional são executados de forma indireta por meio da celebração de convênios com entidades de assistência social, o que leva a questionamentos sobre a efetiva complementariedade ou transferência de responsabilidades.

Soma-se a isso, a problematização sobre o repasse de recursos a entidades conveniadas na área de assistência social que atendem pessoas com deficiência no DF. Pesquisa de Freitas (2011) identificou que, em 2008 e 2009, a maior parte dos valores destinados à Proteção Social Especial foram para o serviço de acolhimento institucional destinado às pessoas com deficiência e, em 2010, o maior montante foi para o serviço de habilitação e reabilitação de pessoa com deficiência. Tem-se aí que "[...] a assistência social é objeto de investimento do setor privado no DF" (FREITAS, 2011, p. 179).

Duarte (2013) corrobora esta análise ao afirmar que o Governo do Distrito Federal (GDF) implementa a Política de Assistência Social em um sistema de parceria com entidades da sociedade civil por meio de convênios firmados via editais de chamamento para seleção pública e contratos, de modo a assegurar a prestação de serviços nesta área. Isso significa uma proposta de partilha e também de ampliação de responsabilidades do privado em detrimento do público, com estímulo ao papel dos setores informais e de voluntariado na configuração do direito à assistência social. 
Considerando o cenário apresentado, busca-se qualificar a análise a partir das compreensões de gestores públicos e de entidades da sociedade civil sobre a prestação de serviços para pessoas com deficiência.

\section{OS SIGNIFICADOS DA RELAÇÃO ENTRE ESTADO E SOCIEDADE CIVIL}

A maioria dos entrevistados reconhece que as entidades desempenham um papel que deveria ser do Estado. Há, porém, interpretações diferenciadas sobre as razões para essa omissão do Estado frente a atuação da sociedade civil. Em alguns casos, destacou-se a insuficiência da atuação pública: "O Estado tem que ver isso com bons olhos. As instituições elas desenvolvem um papel que o governo não consegue fazer." (Entrevistado 7). Em outros, foi enfatizada a omissão do Estado por falta de compromisso e interesse com a garantia de direitos a este público: "Então, o Estado ele faz porque é uma obrigação, né, por essas pessoas. O papel do Estado é esse. Tanto é que deveria existir uma instituição do Estado, mas não interessa e vai par o terceiro setor, né." (Entrevistado 23).

É possível identificar “[...] um discurso da insuficiência estatal [...]”, apresentado por Ferreira (2012, p. 117) em pesquisa com entidades da sociedade civil que atuam na área da assistência social do DF. Soma-se a isto uma descrença no Estado juntamente com uma super confiança na sociedade civil, que marca uma "[...] cultura privatizante no âmbito dos serviços sociais" (FERREIRA, 2012, p. 124). Essa relação entre Estado e sociedade civil torna-se uma compra por serviço, o que reforça seu caráter mercadológico.

A ausência de políticas públicas de proteção social por parte do Estado confere, portanto, prestígio e reconhecimento às entidades. Nesse sentido, algumas delas afirmam que o papel do Estado deveria ser ampliar e amparar o trabalho realizado por tais organizações, que já possuem um histórico de atendimento na área e conhecimentos especializados, ao invés de serem criados serviços públicos. Este é um dos mais significativos tensionamentos na atuação das entidades da sociedade civil na proteção social para pessoas com deficiência.

Nesse aspecto identificam-se as funcionalidades do terceiro setor para a conjuntura contemporânea apresentadas por Duarte (2013) em duas dimensões: o processo de dimensionamento do Estado, minimizando a sua intervenção no enfrentamento às expressões da questão social e contribuindo para o tensionamento entre público e privado; e a promoção de um clima de aliança e igualdade entre as classes sociais, que obscurece conflitos e fragiliza lutas por direitos sociais e a resistência dos trabalhadores.

Na realidade, as fronteiras entre o público e o privado tornam-se imprecisas, o que tem se expresso na literatura com termos como privado porém público (FERNANDES, 1994) e público porém privado (MONTAÑO, 2010). A entrevistada 29 sintetiza esta crítica:

O que eu posso ver é que aqui, pelo menos o que eu vejo, só tem instituições não governamentais que atendem pessoas com deficiência 
aqui no DF. Então, assim, acaba que a assistência ela ficou mesmo por conta pelas instituições não-governamentais. E aí, isso pode ter uma crítica, né, no ponto de vista de que o Estado deveria atender. Mas acaba que elas cumprem um papel importante. [...] E como o Estado não veio fazendo isso durante todos esses anos, houve um incentivo para a iniciativa privada, digamos assim. Então, eu também vejo, assim, poderia ter instituições do Estado, sabe. Porque tem essa discussão né, de tipo assim, "Ah, mas a instituição é privada e recebe recurso do Estado." (Entrevistada 29, grifos nossos).

\section{CONVÊNIOS E REPASSES DE RECURSOS PÚBLICOS}

A atuação do Estado na proteção social para pessoas com deficiência acaba se materializando por meio de um mecanismo de apoio às entidades, que historicamente atuam nesse campo, e não diretamente às pessoas. Em outras palavras, os demandatários imediatos dos recursos públicos são as entidades da sociedade civil e não a população (SPOSATI, 2008). Nos termos de Mestriner (2001), "O reconhecimento estatal das necessidades da população permaneceu, portanto, mediado por organizações, truncando a possibilidade de efetivação da cidadania dos segmentos fragilizados" (MESTRINER, 2001, p. 19).

A parceria é substituída pela delegação, na qual as entidades assumem a responsabilidade integral pelos serviços mediante o repasse de recursos públicos. São estas organizações que compõe em sua amplitude a rede de proteção social para esse segmento: "Porque imagina se não tivesse, se não tivéssemos nós, essas instituições que trabalham com esse público. Como que seria?" (Entrevistada 18). Outra entrevistada complementa: "Então, eu me considero parte de uma rede, de uma rede que o Estado não tem." (Entrevistada 24). Em síntese: “Então, a gente percebe que no combo geral o Estado se beneficia também da atuação dessas entidades, né." (Entrevistado 14).

Ocorre que convênios com o GDF são uma importante fonte de recurso para a manutenção dessas entidades, ao lado de doações de pessoas físicas, outras entidades e/ou empresas; a venda de produtos e oferta de cursos; a organização de eventos como bazares e almoços, e ainda a cobrança de mensalidade de sócios e/ou usuários. Fontes de recursos semelhantes foram encontradas em Souza (2001) e Coelho et al. (2001).

Cabe destacar que há duas formas de convênio com o GDF. No primeiro, com a Secretaria de Estado de Educação, ocorre a cessão de professores para as entidades que realizam atividades educacionais. A Resolução $n^{\circ}$ 01/2017 do Conselho de Educação do DF deixa clara a possibilidade de serem realizadas parcerias no seguinte artigo: "Art. $4^{\circ} \mathrm{O}$ poder público pode firmar convênios e contratos com instituições privadas de ensino ou organizações não governamentais, visando garantir ampliação do atendimento educacional especializado" (DISTRITO FEDERAL, 2017, não paginada, grifos nossos). No segundo, por meio da Secretaria Adjunta de Políticas para as Mulheres, Igualdade Racial e Direitos Humanos (SEDESTMIDH), é repassado um valor fixo per capita de acordo com o plano de trabalho e o quantitativo de pessoas atendidas na área de assistência social. Como sintetiza um entrevistado: 
"O (convênio) da assistência é recurso financeiro e o de educação é recurso de profissionais, né, professores especialistas na área da deficiência." (Entrevistada 17).

A relação entre as entidades e o GDF é complexa e permeada por contradições. Se por um lado, observa-se que os convênios com o poder público são as fontes de recurso mais relevantes na opinião dos entrevistados, já que possuem maior constância e possibilitam uma certa segurança orçamentária; por outro, várias são também as críticas quanto ao valor pago às instituições e aos atrasos nos repasses.

Diversos entrevistados consideraram o valor per capita pago como insuficiente para cobrir todos os custos envolvidos no funcionamento da organização. Souza (2001), em pesquisa realizada com dirigentes de entidades privadas prestadoras de serviço socioassistencial no DF, também apontou como um dos problemas o baixo valor dos recursos repassados pelo governo distrital.

Na fala dos entrevistados: "O recurso do convênio não é suficiente. E a gente também não conta só com ele, né. A gente conta com os nossos parceiros, com os próprios associados da instituição que são as mães e os pais. Eles colaboram nesse sentido." (Entrevistada 18); "O recurso ele é hoje insuficiente pra instituição porque eles pagam pouco, né. E hoje ele tá praticamente $97 \%$ pra folha de pagamento de funcionários e a gente sabe que o lugar aqui, você vai ver, é grande e tem muita necessidade de manutenção, né, muita mesmo." (Entrevistado 23); "O Estado tem que pagar de forma mais adequada, ainda não paga de forma adequada. Os per capitas não atendem tudo que precisa ser feito, né." (Entrevistado 6).

Entre os entrevistados houve relatos de atraso no repasse dos recursos, o que dificulta a continuidade na prestação dos serviços. Uma entrevistada citou inclusive casos de paralisação dos serviços e greves das entidades como estratégia de pressão para que o GDF realizasse os pagamentos devidos: "Aí, a gente faz mobilização de todas as instituições. E aí, constantemente tem reuniões. Aí, assim, nas reuniões fala: Vamos fazer uma greve das instituições!" (Entrevistada 29). Nesse caso, a postura de enfrentamento ao Estado busca atender os interesses das instituições primeiramente e, como consequência, é garantida a continuidade dos serviços à população.

Em 2 de fevereiro de 2018 foi publicada reportagem sobre os atrasos nos repasses do GDF para as entidades da sociedade civil no Jornal Correio Braziliense, sendo afirmado que: "Segundo os gestores dessas entidades, demoras nas transferências de recursos são frequentes e atrapalham rotinas administrativas, como pagamentos de salários de funcionários e de contas de água, luz e telefone. A situação impacta o atendimento aos assistidos e preocupa seus familiares" (ROCHA, 2018, não paginado). Situações semelhantes foram apresentadas por entrevistados da pesquisa: "Até mesmo nós estamos com atraso de quase um mês e meio de repasse do governo do recurso, né. Então, a instituição ela precisa ter um fundo emergencial que a instituição hoje não tem. Está tentando fazer. A gente faz eventos como bazar, rifas, festas, pra arrecadar fundos." (Entrevistada 17). 
Complementar a isso, uma das questões que apareceu nas entrevistas refere-se à gratuidade e aparência não-mercantil dos serviços realizados. Se para aquelas entidades que possuem convênio com o GDF a remuneração pelo serviço, que é público e visa materializar direitos, ocorre pelo Estado; as que não possuem convênios encontram na cobrança dos serviços uma forma de financiar suas ações. Neste segundo caso, os entrevistados afirmaram ser comum os usuários exigirem que as organizações ofereçam determinado serviço na área social ou forneçam bens para atendimento de necessidades básicas. Entretanto, eles explicaram que a realização das ações por suas entidades está condicionada a existência de recursos, com oferta não obrigatória e que pode ser cessada a qualquer momento. Trata-se de concessão e ajuda por parte das entidades à população, condicionado a sua vontade, e não ao caráter de direito.

\begin{abstract}
Olha, eu acho que as pessoas não entendem na verdade. Porque, para mim, o papel da ONG é ela ajudar a sociedade, assim, quem precisa ela consegue ajudar por ser mais barato e tal. Só que ela não é uma coisa governamental, né. Então, ela não tem uma obrigação de fazer tudo para todo mundo. Se alguém chegar aqui e falar "Olha, eu tô precisando disso" e a gente não tem recurso, a gente não tem essa obrigação. $E$ as pessoas acham que a gente tem a obrigação de fazer tudo por todo mundo sem ter recurso, sem nada. É difícil, né, porque a gente vê que o governo não tá fazendo. Infelizmente. (Entrevistada 37, grifos nossos).
\end{abstract}

Eles [os usuários] querem que a gente procure médicos e procura ajudar e cestas básicas, em dar bengalas, dar esse tipo de coisa. $\mathrm{E}$ a gente não tem recursos. Então, é uma coisa eu queria ajudar, mas eu não consigo porque o recurso é pouco. (Entrevistada 20).

Por ser uma ONG, chega gente aqui que acha que o trabalho é totalmente de graça. Aí, não quer pagar, não quer ajudar, não quer fazer doação. Só quer receber o serviço. Tipo, "é uma ONG, então eu quero". E não é assim, entendeu. (Entrevistada 37).

Nesse cenário, em que as entidades da sociedade civil são responsáveis por uma parcela de atendimentos públicos, por meio de convênios com o GDF, é necessário questionar o que dá esse caráter público e de direito para a proteção social. Algumas entidades propõe como alternativa para a falta de recursos a cobrança de uma taxa ou uma mensalidade aos usuários, que em sua maioria são pobres e não encontram outras formas de acessar os serviços se não estas prestadas pelas entidades. Houve inclusive críticas à falta de colaboração por parte dos usuários, que seriam coresponsáveis pelo financiamento das entidades:

Estas são expressões da impossibilidade das entidades da sociedade civil garantirem direitos. Isso não significa que tais ações não sejam relevantes e nem que não tenham impacto na vida concreta das pessoas. Entretanto, não podem ser as únicas fontes de atendimento às necessidades sociais. Conforme explicita Pereira (2016), compete ao Estado a satisfação das necessidades humanas, uma vez que elas são a base das políticas públicas e da concretização de direitos sociais conquistados pela sociedade e declarados em lei. 
Uma das dificuldades de se superar isto é o próprio processo histórico atrelado à filantropia e ao assistencialismo, e não à garantia de direitos (MESTRINER, 2001; SPOSATI, 2008). Soma-se a isto o sentimento de gratidão e de dívida pelo favor prestado, e não da autonomia pelo direito conquistado (SOUZA, 2001). A entrevistada 17 explicou as contradições entre o assistencialismo e a garantia de direitos na visão dos usuários atendidos por sua entidade:

\begin{abstract}
Mas ainda assim eles [os usuários] veem muito assistencialismo. Eles acham que a instituição é obrigada a dar a cesta básica, dar o lanche, dar tudo, né. Elas não veem, elas acham que o que a gente oferece aqui, o serviço, é assistencial mesmo. Não é como uma garantia de direito. Porque a gente só vem a garantir o direito que a pessoa com deficiência tem de receber o atendimento especializado. Então, eles veem muito isso. Acho que todas as instituições, né, elas são vistas com muito assistencialismo (Entrevistada 17, grifos nossos).
\end{abstract}

Em síntese, os entrevistados afirmaram que os recursos financeiros são a principal dificuldade para manter as entidades em funcionamento. Nesse sentido, Coelho et al. (2001) explicam que a fragilidade das receitas das instituições compromete a efetividade, continuidade e qualidade dos serviços prestados. A entrevistada 29 explicou estar vivendo um dilema entre a falta de recursos e as demandas por atendimento: "A instituição tem, assim, uma visão de "vamos atender todo mundo". Só que aí, tem uma hora que não dá, que é o que a gente tá chegando agora." (Entrevistada 29).

\title{
A ATUAÇÃO DO VOLUNTARIADO
}

Diante das fragilidades financeiras, o voluntariado se apresenta como forma de suprir diferentes carências, estando presente em todas as entidades. De acordo com pesquisa do Instituto Brasileiro de Geografia e Estatística (2015), 77,1\% das entidades de assistência social privadas sem fins lucrativos do país possuem trabalho voluntário. A entrevistada 39 enfatiza a importância deste trabalho: "Acho que o voluntário ele é importante. Essa parte aí do voluntariado ele sustenta toda ONG. Eu acho que não tem jeito de ter uma ONG que não tenha voluntariado não." (Entrevistada 39). Outra entidade funciona exclusivamente com trabalho voluntário: "E todas as coisas aqui é doação e todas as pessoas que tem aqui são voluntários. Desde a pessoa que limpa ao cozinheiro, a secretária, o pessoal da oficina, é todo mundo é voluntário. Todo mundo trabalha de coração." (Entrevistado 12).

Segundo Coelho et al. (2001), nas entidades do terceiro setor, o voluntariado se expressa por doações financeiras, de força de trabalho ou mesmo de conhecimentos em função de causas sociais. Essa diversidade de formas de atuação foi identificada na presente pesquisa. Percebeu-se que sua atuação é realizada tanto em trabalhos eventuais e esporádicos quanto em atividades cotidianas das instituições. Dentre elas estão: manutenção da estrutura física da entidade, como mutirão para limpeza e pintura; realização de visita a pessoas em situação de acolhimento institucional; atuação como família hospedeira no treinamento de cães-guia; desenvolvimento de projetos específicos, principalmente nas áreas de artes e esporte; leitura de livros 
para pessoas com deficiência visual; e também realização de atendimentos por profissionais voluntários em diversas áreas, com destaque para a saúde.

Pesquisa de Landim e Scalon (2000) observa que a maior parte das atividades voluntárias exige baixa escolaridade, sendo menor a frequência de trabalho voluntário relacionado a prestação de serviços profissionais. No entanto, na presente pesquisa foi identificado que em diversas entidades existem profissionais de saúde voluntários, principalmente médicos e dentistas: "O voluntariado ocupa quase $50 \%$ dos atendimentos da instituição. É de suma importância e é sempre bem-vindo. Quando a gente não consegue na rede pública, a gente recorre a eles [médicos voluntários]. Eles têm um papel fundamental nas organizações não governamentais." (Entrevistada 25); "Nós temos um médico clínico geral voluntário aqui que faz as atualizações das receitas, né, pra gente. [...] O doutor aqui ele é voluntário. Ele vem duas vezes na semana ainda." (Entrevistada 17).

Os voluntários auxiliam ainda com doações de diversos materiais para as entidades, dentre eles, alimentos, materiais de higiene pessoal, cadeiras de rodas e bengalas, medicamentos. Tratam-se daqueles bens que expressam $\mathrm{O}$ atendimento às necessidades mais básicas de sobrevivência (LANDIM; SCALON, 2000): "A rede pública é um transtorno. Por isso a gente buscou os voluntários. Não tem medicamentos, fraldas. Por isso que precisa dos voluntários, para ajudar com as doações e os recursos." (Entrevistada 25); "E aí, [o voluntário] chega aqui, vê a situação e aí: "Vocês estão precisando do quê?" Aí, a gente fala. Às vezes, um papel. Às vezes, um deficiente visual precisa de uma bengala. A gente mesmo vai falando, né. E aí ajuda.” (Entrevistado 28); “A gente tem voluntários. Quando a gente pode, a gente ajuda em benefícios, em bengalas, ponteiras, cestas básicas." (Entrevistada 20). O voluntariado cobre, portanto, lacunas do Estado tanto na oferta de serviços quanto na oferta de bens que atendam necessidades básicas das pessoas com deficiência.

Ao se situar na tênue fronteira entre o público e o privado, o voluntariado ao mesmo tempo é apresentado como dever cívico e de cidadania que expressa preocupação com aqueles menos favorecidos, e como uma forma de desresponsabilização do Estado, que busca novas formas para o atendimento das expressões da questão social. Bonfim (2010) chama atenção para a história do voluntariado no Brasil, que tem aproximação com práticas assistencialistas, paternalistas e clientelistas, desenvolvidas por instituições religiosas ou das damas da sociedade, orientadas por valores morais.

Embora seja destacada a importância desse trabalho nas instituições, também foram abordados os seus limites. Para o Entrevistado 38 ainda não existe no Brasil a cultura se colaborar com entidades da sociedade: "Nós não temos cultura de voluntariado no Brasil, não temos cultura de, sabe, você colaborar." (Entrevistado 38). Outro entrevistado também disse: "Quem é essa instituição? O que que eles vão fazer com o nosso dinheiro? Você acha que vai dar algum resultado? O brasileiro é assim. Se falar que é uma ONG, acabou, porque ninguém quer ajudar." (Entrevistado 26). 


\section{CONSIDERAÇÕES FINAIS}

O presente artigo buscou analisar as relações entre Estado e sociedade civil na proteção social para pessoas com deficiência no DF. Para tanto, partiu da análise do marco legal e normativo vigente, que desde os anos 1980 apresenta a possibilidade de atuação conjunta na prestação de serviços para atendimento deste público.

A partir dos anos 2000, essas relações se aprofundaram por meio da possibilidade de serem firmados convênios e contratos, à luz do Estatuto do Portador de Necessidades Especiais do DF (Lei $n^{\circ}$ 3.939/2007), a Política de Assistência Social do DF (Lei $n^{\circ}$ 4.176/2008) e a Política Distrital para Integração da Pessoa com Deficiência (Lei $n^{\circ} 4.317 / 2009$ ). Identifica-se um projeto político instituído por meio de leis que visa a ampliação das responsabilidades do setor privado em detrimento do público na configuração da rede de atendimento para pessoas com deficiência no DF.

Os dados obtidos nas entrevistas com gestores públicos e de entidades da sociedade civil possibilitam uma análise qualificada desta realidade. Destaca-se que os significados da relação entre Estado e sociedade civil no campo de estudo são permeados por contradições e argumentos que deslegitimam a atuação estatal a partir de discursos sobre sua insuficiência ou omissão diante da garantia de direitos às pessoas com deficiência.

As fronteiras entre o público e privado se tornam tênues por meio dos processos de convênios e contratação de serviços a estas entidades e repasse de recursos públicos. Nesse sentido, destaca-se que são as entidades da sociedade civil que compõe a maior parte da rede de proteção social para este segmento, amparada por repasses públicos direto de recursos ou por meio da cessão de profissionais, como é o caso do campo da educação.

As contradições identificadas nas falas dos entrevistados se referem ao valor insuficiente dos valores pagos para cobrir os custos de funcionamento das entidades e os atrasos nos repasses. Tem-se aí inclusive relatos de mobilizações e estratégias de pressão como paralisação dos serviços e greves. No caso de entidades que não possuem convênios com o GDF e não recebem recursos para a prestação de serviços, destaca-se o caráter de concessão e ajuda, bem como a impossibilidade dessas organizações garantirem direitos.

Por fim, foi abordada a atuação do voluntariado, presente em todas as entidades analisadas, como uma estratégia para suprir carências tanto na prestação de serviços profissionais, com destaque para a área da saúde, quanto para a oferta de bens que atendam necessidades básicas dos usuários dos serviços.

\section{REFERÊNCIAS}

BLANCO, Marisa Revilla. Zona peatonal. Las ONG como mecanismos de participación política. In: BLANCO, Marisa Revilla (Ed.). Las ONG y la política. Detalles de una relación. Madrid: Ediciones Istmo, 2002. 


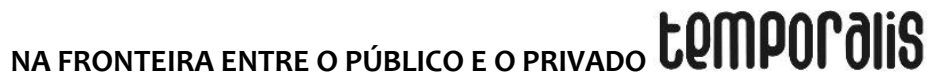

BRASIL. Ministério do Desenvolvimento Social e Combate à Fome. Política Nacional de Assistência Social PNAS/2004. Brasília (DF), 2009.

BRASIL. Presidência da República. Decreto $n^{\circ}$ 6.949, de 25 de agosto de 2009. Promulga a Convenção Internacional sobre os Direitos das Pessoas com Deficiência e seu Protocolo Facultativo, assinados em Nova York, em 30 de março de 2007. Brasília (DF), 2009. Disponível em: http://www.planalto.gov.br/ccivil_03/_at020072010/2009/decreto/d6949.htm. Acesso em: 15 jul. 2016.

BRASIL. Lei $\mathbf{n}^{\circ} \mathbf{8 . 7 4 2}$, de 7 de dezembro de 1993. Dispõe sobre a organização da Assistência Social e dá outras providências. Brasília (DF), 1993. Disponível em: http://www.planalto.gov.br/ccivil_03/leis/18742.htm. Acesso em: 4 maio 2020.

BONFIM, Paula. A “cultura do voluntariado” no Brasil. São Paulo: Cortez, 2010.

CABRAL FILHO, Adilson Vaz; FERREIRA, Gildete. Movimentos sociais e o protagonismo das pessoas com deficiência. Ser Social, Brasília (DF), v. 15, n. 32, p. 93-116, jan./jul. 2013. Disponível em:

https://periodicos.unb.br/index.php/SER_Social/article/view/13036/11391. Acesso em: 28 mai. 2016.

COELHO, Ailta Barros de S. R. et al. Infância, adolescência e terceiro setor no Distrito Federal. Ser Social, Brasília, n. 9, 2001. Disponível em:

http://repositorio.unb.br/bitstream/10482/8415/1/ARTIGO_InfanciaAdolescenciaTerc eiroSetor.pdf. Acesso em: 13 dez. 2017.

DINIZ, Debora; SANTOS, Wederson. Deficiência e direitos humanos: desafios e respostas à discriminação. In: DINIZ, Debora; SANTOS, Wederson (Org.). Deficiência e discriminação. Brasília (DF): Letras Livres; EdUnB, 2010.

DUARTE, Janaína Lopes do Nascimento. Entre o público e o privado: reflexões sobre o significado das Entidades Beneficentes no contexto do SUAS no Distrito Federal.

Rev. Pol. Públ. São Luis, v. 17, n. 2, p. 424-435, jul./dez. 2013.

FERNANDES, Rubem César. Privado porém público: o terceiro setor na América Latina. 2. ed. Rio de Janeiro: Relume-Dumará, 1994.

FERREIRA, Monica Danielle Maciel. As contradições ideopolíticas em torno da assistência social a partir da década de 90: vozes e perspectivas das entidades privadas do DF. 2012. Dissertação (Mestrado em Política Social)-Universidade de Brasília, Brasília (DF), 2012.

FREITAS, Nathalia Eliza. A materialização do SUAS no DF: o Estado garantindo a primazia do setor privado. 2011. Dissertação (Mestrado em Política Social)Universidade de Brasília, Brasília (DF), 2011. 
FIGUEIRA, Emilio. Caminhando em silêncio: uma introdução à trajetória das pessoas com deficiência na história do Brasil. 2. ed. São Paulo: Giz Editora, 2008.

GADELHA, Crismere; CRESPO, Lia; RIBEIRO, Suzada. Memórias da Luta: Protagonistas do AIPD. In: SÃO PAULO (Estado). Secretaria dos Direitos da Pessoa com Deficiência. Memorial da Inclusão. 30 anos do AIPD: Ano Internacional das Pessoas Deficientes 1981-2011. São Paulo: Imprensa Oficial do Estado de São Paulo, 2011.

DISTRITO FEDERAL (Brasil). Conselho de Educação do Distrito Federal. Resolução $\mathbf{n}^{\circ}$ 1, de 28 de março de 2017. Estabelece normas para a Educação Especial no Sistema de Ensino do Distrito Federal e dá outras providências. Brasília (DF), 2017. Disponível em: https://www.legisweb.com.br/legislacao/?id=342172. Acesso em: 18 out. 2017.

DISTRITO FEDERAL (Brasil). Plano Distrital de Políticas Públicas para Pessoas com Deficiência: Viver sem Limites Brasília (DF): GDF, 2013.

DISTRITO FEDERAL (Brasil). Lei $\mathbf{n}^{\circ}$ 4.317, de 9 de abril de 2009. Institui a Política Distrital para Integração da Pessoa com Deficiência, consolida as normas de proteção e dá outras providências. Brasília (DF), 2009. Disponível em:

http://www.sinj.df.gov.br/sinj/Norma/60186/Lei_4317_09_04_2009.html. Acesso em: 24 ago. 2017.

DISTRITO FEDERAL (Brasil). Lei $\mathbf{n}^{\circ} \mathbf{4 . 1 7 6}$, de 16 de julho de 2008. Dispõe sobre a Política de Assistência Social do Distrito Federal, institui o Sistema Único de Assistência Social no Distrito Federal e dá outras providências. Brasília (DF), 2008. Disponível em: http://www.sinj.df.gov.br/sinj/Norma/58126/Lei_4176_ 16_07_2008.pdf. Acesso em: 25 out. 2017.

DISTRITO FEDERAL (Brasil). Lei nº 3.939, de 2 de janeiro de 2007. Institui o Estatuto do Portador de Necessidades Especiais e dá outras providências. Brasília (DF), 2007. Disponível em:

http://www.sinj.df.gov.br/sinj/Norma/54438/Lei_3939_02_01_2007.html. Acesso em: 15 out. 2017.

DISTRITO FEDERAL (Brasil). Lei Orgânica do Distrito Federal. Brasília (DF), 8 jun. 1993. Disponível em:

http://www.sinj.df.gov.br/sinj/Norma/66634/Lei_Org_nica_08_06_1993.html. Acesso em 11 fev. 2018.

DISTRITO FEDERAL (Brasil). Decreto $\mathbf{n}^{\circ} \mathbf{1 1 . 1 0 7}$, de 18 de maio de 1988. Dispõe sobre as ações da Administração do Distrito Federal relativas às pessoas portadoras de deficiência e dá outras providências. Brasília (DF), 1988. Disponível em: http://www.sinj.df.gov.br/sinj/Norma/16122/Decreto_11107_18_05_1988.html. Acesso em: 12 out. 2017. 


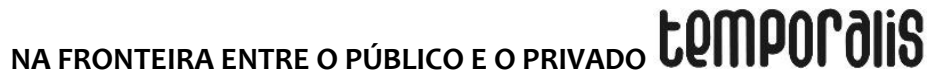

INSTITUTO BRASILEIRO DE GEOGRAFIA E ESTATÍSTICA. As Entidades de Assistência Social Privadas sem Fins Lucrativos no Brasil 2014-2015: unidades de prestação de serviços socioassistenciais. Rio de Janeiro: IBGE, 2015. Disponível em:

https://biblioteca.ibge.gov.br/visualizacao/livros/liv94686.pdf. Acesso em 18 jul. 2017.

LANDIM, Leilah. As ONGs são terceiro setor? In: ONGs no Brasil: perfil de um mundo em mudança. Fortaleza: Fundação Konrad Adenauer, 2003.

LANDIM, Leilah; SCALON, Maria Celi. Doações e trabalho voluntário no Brasil: uma pesquisa. Rio de Janeiro: 7Letras, 2000.

LANNA JÚNIOR, Mário Cléber Martins (Comp.). História do Movimento político das pessoas com deficiência no Brasil. Brasília (DF): SDH-SNPD, 2010.

LAURELL, Asa Cristina. Avançando em direção ao passado: a política social do neoliberalismo. In: LAURELL, Asa Cristina (Org.). Estado e políticas sociais no neoliberalismo. São Paulo: Cortez, 1995.

MAIOR, Izabel M. M. de Loureiro. Políticas públicas sociais para as pessoas portadoras de deficiência no Brasil. Cadernos de Pesquisa, n. 7, maio 1997.

MELLO, Anahi Guedes de. Deficiência, incapacidade e vulnerabilidade: do capacitismo ou a preeminência capacitista e biomédica do Comitê de Ética em Pesquisa da UFSC. Ciência \& Saúde Coletiva, Rio de Janeiro, v. 21, n. 10, p. 3265-3276, out. 2016. Disponível em:

https://www.scielo.br/j/csc/a/J959p5hgv5TYZgWbKvspRtF/abstract/?lang=pt. Acesso em 24 out. 2016.

MESTRINER, Maria Luiza. O Estrado entre a filantropia e a assistência social. São Paulo: Cortez, 2001.

MONTAÑO, Carlos. Das “lógicas do Estado" às “lógicas da sociedade civil”: Estado e “terceiro setor” em questão. Serviço Social \& Sociedade, São Paulo, n. 59, 1999.

MONTAÑO, Carlos. Terceiro setor e questão social: crítica ao padrão emergente de intervenção social. 6. ed. São Paulo: Cortez, 2010.

NEVES, Angela Vieira. Cultura política e democracia participativa: um estudo sobre o orçamento participativo. Rio de Janeiro: Gramma, 2008.

NEVES, Angela Vieira. Espaços públicos e práticas políticas: os riscos de despolitização da participação da sociedade civil. In: DAGNINO, Evelina; TATAGIBA, Luciana (Orgs). Democracia, sociedade civil e participação. Chapecó: Argos, 2007.

NOGUEIRA, Marco Aurélio. Um Estado para a sociedade civil: temas éticos e políticos da gestão democrática. 3. ed. São Paulo: Cortez, 2011. 
PEREIRA, Camila Potyara. Proteção Social no Capitalismo: críticas a teorias e ideologias conflitantes. São Paulo: Cortez, 2016.

ROCHA, Ludmila. GDF atrasa repasse a instituições que atendem pessoas de baixa renda. Correio Braziliense, Brasília (DF), 2 fev. 2018. Disponível em: https://www.correiobraziliense.com.br/app/noticia/cidades/2018/02/02/interna_cida desdf,657348/gdf-atrasa-repasse-a-instituicoes-que-atendem-pessoas-de-baixarenda.shtml. Acesso em 3 fev. 2018.

SOUZA, Ênia Maria de. A ação das entidades não-governamentais na área da assistência social no Distrito Federal: direito ou filantropia? 2001. Dissertação (Mestrado em Política Social)-Universidade de Brasília, Brasília (DF), 2001.

SPOSATI, Aldaíza de Oliveira. A assistência social e a trivialização dos padrões de reprodução social. In: SPOSATI, Aldaíza; FALCÃO, Maria do Carmo; TEIXEIRA, Sônia Maria Fleury. Os direitos (dos desassistidos) sociais. 6. ed. São Paulo: Cortez, 2008.

TEIXEIRA, Ana Cláudia Chaves. A atuação das Organizações Não-Governamentais: entre o Estado e o conjunto da sociedade. In: DAGNINO, Evelina (Org.). Sociedade civil e espaços públicos no Brasil. São Paulo: Paz e Terra, 2002.

YASBEK, Maria Carmelita. A política social brasileira nos anos 90: a refilantropização da questão social. Cadernos ABONG, São Paulo: ABONG, out. 1995.

Thaís Kristosch Imperatori Trabalhou na análise e interpretação dos dados, assim como na redação do artigo.

Assistente Social. Possui graduação em Serviço Social e Ciências Sociais pela Universidade de Brasília (UnB), Mestrado e Doutorado em Política Social pela mesma instituição. Professora do Departamento de Serviço Social da UnB. Líder do Grupo de Estudos e Pesquisas sobre Democracia, Sociedade Civil e Serviço Social (GEPEDSS) e tutora do grupo de Serviço Social do Programa de Educação Tutorial da UnB.

Angela Vieira Neves Trabalhou na revisão crítica e aprovação da versão a ser publicada.

Assistente Social. Possui graduação em Serviço Social pela Universidade Federal Fluminense (UFF), Mestrado em Serviço Social pela Pontifícia Universidade Católica do Rio de Janeiro (PUC-Rio) e Doutorado em Ciências Sociais pela Universidade Estadual de Campinas (Unicamp). Realizou estágio de pós-doutorado na Pontifícia Universidade Católica do Rio de Janeiro (PUC-Rio). Professora aposentada do Departamento de Serviço Social da Universidade de Brasília (UnB). Atualmente é Professora colaboradora do Programa de Pós-Graduação em Política Social da UnB (PPGPS/SER/UNB). Líder do Grupo de Estudos e Pesquisas sobre Democracia, Sociedade Civil e Serviço Social (GEPEDSS). 